\title{
The role of hydrological transience in peatland pattern formation
}

\author{
P. J. Morris ${ }^{1}$, A. J. Baird ${ }^{2}$, and L. R. Belyea ${ }^{3}$ \\ ${ }^{1}$ Soil Research Centre, Department of Geography and Environmental Science, University of Reading, \\ Reading, RG6 6DW, UK \\ ${ }^{2}$ School of Geography, University of Leeds, Leeds, LS2 9JT, UK \\ ${ }^{3}$ School of Geography, Queen Mary University of London, 327 Mile End Road, London, E1 4NS, UK
}

Correspondence to: P. J. Morris (p.j.morris@ reading.ac.uk, paul.john.morris@gmail.com)

Received: 7 May 2013 - Published in Earth Surf. Dynam. Discuss.: 6 June 2013

Revised: 18 September 2013 - Accepted: 30 September 2013 - Published: 16 October 2013

\begin{abstract}
The sloping flanks of peatlands are commonly patterned with non-random, contour-parallel stripes of distinct micro-habitats such as hummocks, lawns and hollows. Patterning seems to be governed by feedbacks among peatland hydrological processes, plant micro-succession, plant litter production and peat decomposition. An improved understanding of peatland patterning may provide important insights into broader aspects of the long-term development of peatlands and their likely response to future climate change.

We recreated a cellular simulation model from the literature, as well as three subtle variants of the model, to explore the controls on peatland patterning. Our models each consist of three submodels, which simulate: peatland water tables in a gridded landscape, micro-habitat dynamics in response to water-table depths, and changes in peat hydraulic properties.

We found that the strength and nature of simulated patterning was highly dependent on the degree to which water tables had reached a steady state in response to hydrological inputs. Contrary to previous studies, we found that under a true steady state the models predict largely unpatterned landscapes that cycle rapidly between contrasting dry and wet states, dominated by hummocks and hollows, respectively. Realistic patterning only developed when simulated water tables were still transient.

Literal interpretation of the degree of hydrological transience required for patterning suggests that the model should be discarded; however, the transient water tables appear to have inadvertently replicated an ecological memory effect that may be important to peatland patterning. Recently buried peat layers may remain hydrologically active despite no longer reflecting current vegetation patterns, thereby highlighting the potential importance of three-dimensional structural complexity in peatlands to understanding the two-dimensional surface-patterning phenomenon.

The models were highly sensitive to the assumed values of peat hydraulic properties, which we take to indicate that the models are missing an important negative feedback between peat decomposition and changes in peat hydraulic properties. Understanding peatland patterning likely requires the unification of cellular landscape models such as ours with cohort-based models of long-term peatland development.
\end{abstract}

\section{Introduction}

\subsection{Background}

The surface of northern peatlands often comprises a patchwork of distinct, small-scale $(<10 \mathrm{~m}$; known as scale-level 1 , or SL1 - Baird et al., 2009) micro-habitats, each with a char- acteristic vegetation type, micro-topographic relief, watertable and soil-moisture regimes, soil hydraulic properties, and soil biogeochemical regime (Ivanov, 1981; Alm et al., 1997; Belyea and Clymo, 2001; Rydin and Jeglum, 2006). These micro-habitats commonly aggregate into larger spatial 
structures at horizontal scales of tens to hundreds of metres (SL2), often forming landscapes composed of strongly directional, non-random patterns that may be linear and contour parallel, polygonal, or maze like (e.g. Aber et al., 2002; Eppinga et al., 2008; Korpela et al., 2009). Baird et al. (2009) demonstrated that the frequency distribution of water-table depths from across a peatland landscape depends not just on the proportion of the landscape covered by different micro-habitats but also on the pattern. In consequence, pattern may play an important role in determining peatlandatmosphere fluxes of greenhouse carbon gases (carbon dioxide and methane), which vary with water-table depth (Bubier et al., 1993, 1995; Roulet et al., 2007). Additionally, it seems likely that the development and maintenance of peatland patterning is governed by the same mechanisms that control peat accumulation, decomposition, and the development of soil hydraulic properties (Belyea and Clymo, 2001; Nungesser, 2003; Eppinga et al., 2009). An improved understanding of the mechanisms that control patterning may therefore reveal fundamental rules that govern broader aspects of peatland ecosystem and soil development at the landscape scale.

Observational (e.g. Foster and Fritz, 1987; Belyea and Clymo, 2001; Comas et al., 2005) and modelling (e.g. Nungesser, 2003; Swanson, 2007) studies have identified a variety of aspatial or one-dimensional (vertical only) feedback mechanisms that may help to explain directionless clumping of SL1 units into larger features. However, understanding the highly directional nature of patterning seen in many peatlands clearly requires an explicit consideration of spatial interactions. This problem lends itself naturally to investigation using 2- or 3-dimensional simulation models, in which directional transfers of water, energy and nutrients, and their effects on pattern, can be explored directly. Interplay between long- and short-range processes is a recurring theme in many apparently successful models of patterned landscapes, including peatlands (Rietkerk et al., 2004a, b; Eppinga et al., 2009) and other landscape types such as marshes (van de Koppel and Crain, 2006) and drylands (Lefever and Lejeune, 1997).

One current hypothesis on peatland pattern formation, the ponding mechanism, has been explored using cellular landscape models in a number of previous studies. The ponding mechanism consists of a pair of competing feedbacks between water-table depth, peatland micro-habitat succession, and peat hydraulic properties. Areas with deeper water tables are assumed to be more likely to support hummock vegetation, whereas areas with shallower water tables are assumed to be more likely to support hollow vegetation (cf. Rydin and Jeglum, 2006). Furthermore, hummock vegetation is assumed to produce near-surface peat that is less permeable than that produced in hollows (cf. Ivanov, 1981). Contrasting micro-habitat states (hummock, hollow) between adjacent SL1 units allow a positive feedback that reinforces local differences in water tables. Ponding occurs upslope of hummocks, leading to hollows there; while areas downslope of

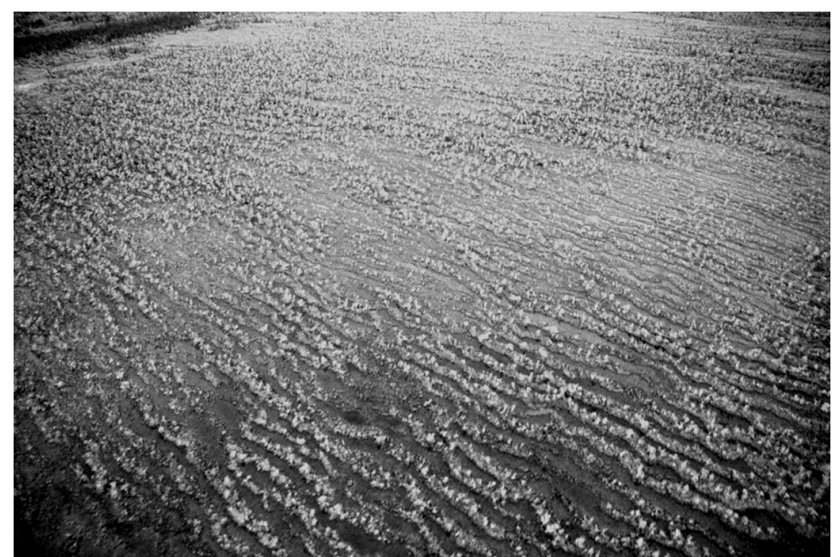

Figure 1. Aerial photograph showing contour-parallel, striped patterning on a peatland complex in the James Bay lowlands, Ontario, Canada. The directions of slope and regional water flow are from the top right to the bottom left of the picture. Horizontal distance between tops of successive ridges is approximately 5 to $10 \mathrm{~m}$. Image belongs to Brian Branfireun, reproduced here with kind permission.

hummocks are deprived of water, encouraging the development of hummocks. Conversely, rapid drainage occurs upslope of hollows, leading to hummocks there; while areas downslope of hollows are supplied readily with water, encouraging the development of hollows. This short-range positive feedback competes against a long-range negative feedback whereby water flow between the model's boundaries tends to homogenise local variations in water tables. Swanson and Grigal (1988), Couwenberg (2005) and Couwenberg and Joosten (2005) found that, when implemented in a numerical cellular landscape in which shallow groundwater flow is predominantly downslope, the ponding mechanism generated realistic-looking, contour-parallel stripes of hummocks and hollows at SL2 (we henceforth refer to these three papers, and the versions of the ponding model that they describe, collectively as SGCJ). However, Eppinga et al. (2009) came to different conclusions when using their own cellular model to explore the individual and combined effects of the ponding mechanism and two other feedbacks. They found that contour-parallel striped patterning such as that shown in Fig. 1 developed under several combinations of these feedbacks, but not when the ponding mechanism alone was used; that is, when using the ponding model in isolation they were unable to find a combination of parameters that generated anything other than a homogeneous, unpatterned landscape, seemingly in disagreement with the earlier studies. Consequently it is difficult to judge whether the ponding mechanism alone still represents a viable theory of peatland patterning. 
Table 1. Glossary of algebraic terms, including default values where appropriate, for each of the four model versions.

\begin{tabular}{|c|c|c|c|c|c|c|c|}
\hline Symbol & Description & Dimensions & Units & Model 1 & Model 2 & Model 3 & Model 4 \\
\hline$B$ & peatland surface height above arbitrary datum & $\mathrm{L}$ & $\mathrm{m}$ & 0.22 to $4.20 \mathrm{~m}$ & 0.22 to $4.20 \mathrm{~m}$ & 0.48 to $4.17 \mathrm{~m}$ & 0.48 to $4.17 \mathrm{~m}$ \\
\hline$\Delta t_{\mathrm{e}}$ & hydrological submodel runtime (steady-state criterion) & $\mathrm{T}$ & $\mathrm{h}$ & 50 & 50 & 50 & $17520(2 \mathrm{yr})$ \\
\hline$d$ & thickness of flow & $\mathrm{L}$ & $\mathrm{m}$ & - & auxiliary variable & auxiliary variable & auxiliary variable \\
\hline$H$ & water-table height above arbitrary datum & $\mathrm{L}$ & $\mathrm{m}$ & auxiliary variable & auxiliary variable & auxiliary variable & auxiliary variable \\
\hline$K$ & hydraulic conductivity & $\mathrm{L} \mathrm{T}^{-1}$ & $\mathrm{~m} \mathrm{~s}^{-1}$ & - & - & - & - \\
\hline$K_{\text {ave }}$ & depth-averaged hydraulic conductivity & $\mathrm{L} \mathrm{T}^{-1}$ & $\mathrm{~ms}^{-1}$ & - & - & - & - \\
\hline$K_{\text {deep }}$ & hydraulic conductivity of deep peat & $\mathrm{LT}^{-1}$ & $\mathrm{~m} \mathrm{~s}^{-1}$ & - & 0 & $1.25 \times 10^{-5}$ & $1.25 \times 10^{-5}$ \\
\hline$K_{\mathrm{hol}}$ & hydraulic conductivity of hollow peat & $\mathrm{LT}^{-1}$ & $\mathrm{~ms}^{-1}$ & - & $1.0 \times 10^{-3}$ & $1.0 \times 10^{-3}$ & $1.0 \times 10^{-3}$ \\
\hline$K_{\text {hum }}$ & hydraulic conductivity of hummock peat & $\mathrm{LT}^{-1}$ & $\mathrm{~m} \mathrm{~s}^{-1}$ & - & $5.0 \times 10^{-5}$ & $5.0 \times 10^{-5}$ & $5.0 \times 10^{-5}$ \\
\hline$p$ & probability of hummock formation & - & - & Eq. (3); Fig. 3 & Eq. (3); Fig. 3 & Eq. (3); Fig. 3 & Eq. (3); Fig. 3 \\
\hline$Q$ & hummock turnover rate & - & - & state variable & state variable & state variable & state variable \\
\hline$\widetilde{R}$ & relative variance of hummocks per row & - & - & state variable & state variable & state variable & state variable \\
\hline$S$ & proportion of model landscape occupied by hummocks & - & - & state variable & state variable & state variable & state variable \\
\hline$\theta$ & peat drainable porosity & - & - & 0.3 & 0.3 & 0.3 & 0.3 \\
\hline$T$ & peat transmissivity & $\mathrm{L}^{2} \mathrm{~T}^{-1}$ & $\mathrm{~m}^{2} \mathrm{~s}^{-1}$ & - & - & - & - \\
\hline$T_{\text {hol }}$ & transmissivity of hollow cells & $\mathrm{L}^{2} \mathrm{~T}^{-1}$ & $\mathrm{~m}^{2} \mathrm{~s}^{-1}$ & $2.0 \times 10^{-4}$ & - & - & - \\
\hline$T_{\text {hum }}$ & transmissivity of hummock cells & $\mathrm{L}^{2} \mathrm{~T}^{-1}$ & $\mathrm{~m}^{2} \mathrm{~s}^{-1}$ & $1.0 \times 10^{-5}$ & - & - & - \\
\hline$U$ & net rainfall rate (precip. minus evapotran.) & $\mathrm{LT}^{-1}$ & $\mathrm{~mm} \mathrm{yr}^{-1}$ & 0 & 0 & 400 (constant) & 400 (time series) \\
\hline$x$ & spatial index (across-slope direction) & $\mathrm{L}$ & $\mathrm{m}$ & - & - & - & - \\
\hline$y$ & spatial index (along-slope direction) & $\mathrm{L}$ & $\mathrm{m}$ & - & - & - & - \\
\hline$Z$ & water-table depth below peat surface & $\mathrm{L}$ & $\mathrm{m}$ & auxiliary variable & auxiliary variable & auxiliary variable & auxiliary variable \\
\hline$Z_{\text {final }}$ & final water-table depth at end of developmental step & $\mathrm{L}$ & $\mathrm{m}$ & state variable & state variable & state variable & - \\
\hline$Z_{\text {mean }}$ & mean water-table depth during second half of dev. step & $\mathrm{L}$ & $\mathrm{m}$ & - & - & - & state variable \\
\hline
\end{tabular}

\subsection{Aim and objectives}

We recreated the SGCJ version of the ponding model to explore three characteristics that we suspected may have individually or collectively led to a Type- 1 error in the SGCJ studies (i.e. causing a model to predict patterning despite the ponding mechanism being incapable of generating patterning in reality):

i. Numerical implementation of shallow groundwater flow: the transmissivity, $T$ [dimensions of $\mathrm{L}^{2} \mathrm{~T}^{-1}$ ] (see Table 1 for a glossary of algebraic terms), of any grid square in the original SGCJ models depends entirely on whether that square is currently a hummock or a hollow. Only two values of $T$ are possible, one canonical value for hummocks, $T_{\text {hum }}$, and one for hollows, $T_{\text {hol }}$. A more realistic scheme would have been to assign canonical values of a more intrinsic property of peat such as saturated hydraulic conductivity, $K_{\text {hum }}$ and $K_{\text {hol }}\left[\mathrm{L} \mathrm{T}^{-1}\right]$, to hummocks and hollows, respectively, and to calculate transmissivity as the product of $K$ and the thickness of flow in that square, thereby allowing for continuous variation in $T$ across the model landscape. We extended the hydrological submodel from the SGCJ models in this way in order to remove any unrealistic constraints that the simplified numerical implementation of shallow groundwater flow may have placed upon overall model behaviour. We also wished to explore the effects of the absolute values of $T$ or $K$ (as appropriate) upon model behaviour.

ii. Conceptual hydrogeological setting: the original SGCJ models considered only a shallow layer of near-surface peat, and assumed that deeper peat was impermeable to groundwater flow. The top few decimetres of peat are usually the most permeable (e.g. Fraser et al., 2001; Clymo, 2004) and are therefore prone to the most rapid subsurface flow, although deeper peat is rarely truly impermeable. Indeed, a number of studies have indicated that drainage through deep peat layers may play an important role in peatland development and the ability of these ecosystems to self-organise (e.g. Ingram, 1982; Belyea and Baird, 2006; Morris et al., 2011). The assumption of impermeable peat below the uppermost few decimetres may have prevented the SGCJ models from representing a potentially important hydrological interaction between surficial hydraulic structures and deeper peat layers. Furthermore, in the original SGCJ models rainfall was not included; the only inputs of water to the models were from shallow groundwater flow and/or surface runon. In order to address these conceptual issues we experimented with the effects of incorporating a permeable lower layer and driving the model using simulated rainfall.

iii. Dependence on hydrological transience: the original SGCJ authors reported that strong striped patterning occurred in their models under "steady-state" hydrological conditions, whereby micro-habitat transitions only took place once the simulated water-table map had equilibrated with with the current distribution of hummocks and hollows (and so the spatial arrangement of transmissivity) (see Sect. 2 for full model description). The criterion used to determine steady state considers the proportion of cells in which the rate of water-table change $\left[\mathrm{L} \mathrm{T}^{-1}\right]$ is less than a threshold rate. Steady-state conditions are deemed to occur when the proportion of cells below the threshold is greater than a proportion set by the model user. However, preliminary experiments 
(not reported here in full) with our own version of the ponding model indicated that the simulations reported in the earlier SGCJ studies may not have attained true hydrological steady state and that, curiously, patterning only developed under intermediate steady-state criteria where water tables were still transient. We chose to experiment with the effects of hydrological transience upon model patterning, either by manipulating the water-table steady-state criterion, or by driving the model with a real time series of rainfall data.

\section{Models and methods}

\subsection{Overview}

We began with a model that was as similar as possible to that employed by Couwenberg (2005), as far as the original model description allows. As well as this replica model (henceforth, Model 1) we created three additional models (Models 2, 3 and 4) with slightly altered routines. We designed Model 2 so as to address the numerical implementation issue identified in objective (i), while we designed Models 3 and 4 so as to address the conceptual issues identified in objective (ii) (see Sect. 1.2, above; and Table 2). Each of the four models may be thought to consist of three submodels that simulate: shallow saturated groundwater movements and the spatial distribution of water-table depths at SL1 (hydrological submodel); switches in micro-habitat type (ecological submodel); and changes in peat soil hydraulic properties (soil properties submodel). Model time progresses in developmental steps: during each developmental step the hydrological submodel is run until a predetermined steady-state criterion is met. The output from the hydrological submodel is a map of water-table depths within the model landscape. The ecological submodel then simulates a new micro-habitat map within the model landscape on the basis of the watertable map, such that every cell in the model landscape is assigned one of two binary micro-habitat types: hummock or hollow. Finally, the soil properties submodel uses the new micro-habitat map to reassign the spatial distribution of nearsurface peat hydraulic properties. The new map of peat hydraulic properties is then used as an input to the hydrological model at the beginning of the next developmental step. As with the SGCJ studies, our models do not simulate explicitly the processes of peat formation or decomposition, and therefore do not incorporate a peat mass balance. Rather, the models represent plant community succession as a shifting mosaic of SL1 tiles superimposed onto a static peat landform.

\subsection{Hydrological submodel}

The hydrological submodel uses a modification of the DigiBog model of peatland saturated hydrology (Baird et al., 2012). We took the original DigiBog Fortran 95 code and added routines to represent the ecological and hydrophysical submodels. In the current study we deactivated DigiBog's peat accumulation, decomposition and hydrophysical subroutines described by Morris et al. (2012). We refer the reader to Baird et al. (2012) for a comprehensive description of DigiBog's governing equations and numerical implementation, although a few points are pertinent here. DigiBog represents a peatland as a grid of vertical peat columns; in plan each column is equivalent to one square grid cell in the SGCJ models, although DigiBog also allows for vertical variation in peat hydraulic properties. Horizontal saturated groundwater flow occurs between adjacent columns (four-square neighbourhood) at a rate equal to the product of the harmonic mean of inter-cell transmissivity (the product of depth-averaged hydraulic conductivity and the thickness of flow) and inter-cell hydraulic gradient, according to the Boussinesq equation (see also McWhorter and Sunada, 1977):

$\frac{\partial H}{\partial t}=\frac{\partial}{\partial x}\left(\frac{K_{\mathrm{ave}}(d)}{\theta} d \frac{\partial H}{\partial x}\right)+\frac{\partial}{\partial y}\left(\frac{K_{\mathrm{ave}}(d)}{\theta} d \frac{\partial H}{\partial y}\right)+\frac{U}{\theta}$,

where $H$ is water-table height [L] above an arbitrary datum; $t$ is simulated time [T]; $x$ and $y$ are across-slope and alongslope horizontal spatial dimensions, respectively [L]; $K_{\text {ave }}$ is depth-averaged hydraulic conductivity $\left[\mathrm{L} \mathrm{T}^{-1}\right] ; \theta$ is drainable porosity of the peat [dimensionless] , assumed constant at 0.3 ; $d$ is thickness of flow [L], defined as the height of the water table, $H$, minus the height of the impermeable base layer; and $U$ is net rainfall $\left[\mathrm{L} \mathrm{T}^{-1}\right]$. Because $U$ is added directly to the saturated zone it may be thought of as a black-box representation of total precipitation minus the sum of surface runoff, interception, evapotranspiration and unsaturated water-storage change.

The hydrological model is run for a predetermined length of simulated time in order to allow the water-table map to change in response to the boundary conditions and the current distribution of hydraulic properties. In Models 1 to 3, the length of time that the hydrological model is allowed to run, $\Delta t_{\mathrm{e}}[\mathrm{T}]$, before an ecological transition takes place (Sect. 2.3) determines how close to a genuine steady state the simulated water tables are. Short equilibration times lead to highly transient water tables that are still changing rapidly and are far from being in equilibrium with the hydrological inputs or boundary conditions; the opposite is true of long runtimes. In Models 1, 2 and 3 we varied $\Delta t_{\mathrm{e}}$ between $1 \mathrm{~h}$ (highly transient water tables) and $10000 \mathrm{~h}$ (approximately 417 days; highly steady water tables) to examine the effect of the steady-state criterion upon model behaviour. We performed only a single simulation with Model 4, with $\Delta t_{\mathrm{e}}=17520 \mathrm{~h}$ (equal to two years of simulated time), and introduced hydrological transience by driving the model using a daily rainfall time series derived from observed data (Sect. 2.5).

We performed a simple test on Models 1, 2 and 3 in order to verify that increasing $\Delta t_{\mathrm{e}}$ led to increasing hydrological steadiness. We ran each model for a spin-up period of 25 
Table 2. Summary of the four models and the objectives addressed by each.

\begin{tabular}{lllllll}
\hline Model & $\begin{array}{l}\text { Transmissivity } \\
\text { scheme }\end{array}$ & Deep peat layer & $\begin{array}{l}\text { Net rainfall, } U \\
\text { (precip. minus evapotran.) }\end{array}$ & $\begin{array}{l}\text { Up-slope boundary } \\
\text { condition }\end{array}$ & $\begin{array}{l}\text { Aquifer } \\
\text { shape }\end{array}$ & $\begin{array}{l}\text { Objectives } \\
\text { addressed }\end{array}$ \\
\hline 1 & binary & impermeable & off & constant head, $Z=0.025 \mathrm{~m}$ & constant slope & iii \\
2 & continuous & impermeable & off & constant head, $Z=0.025 \mathrm{~m}$ & constant slope & i, iii \\
3 & continuous & $K_{\text {deep }}=1.25 \times 10^{-5} \mathrm{~m} \mathrm{~s}^{-1}$ & $400 \mathrm{~mm} \mathrm{yr}^{-1}$ (constant) & impermeable (no-flow) & $\begin{array}{l}\text { hemi-elliptical } \\
\text { i, ii, iii }\end{array}$ \\
4 & continuous & $K_{\text {deep }}=1.25 \times 10^{-5} \mathrm{~m} \mathrm{~s}^{-1}$ & $400 \mathrm{~mm} \mathrm{yr}^{-1}$ (time series) & impermeable (no-flow) & hemi-elliptical & iii \\
\hline
\end{tabular}

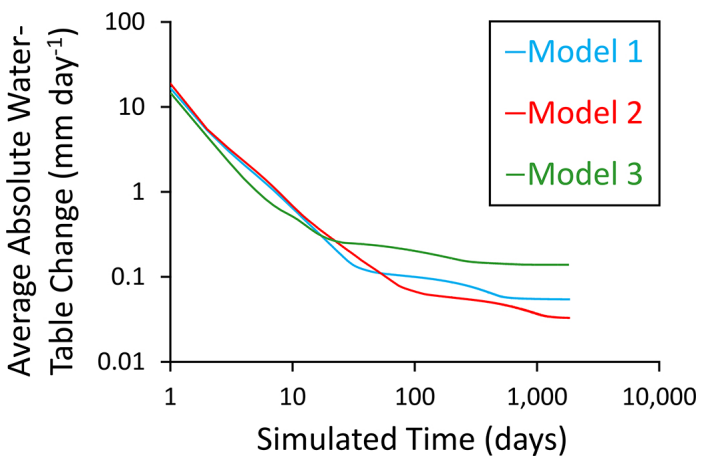

Figure 2. Time series of daily-average absolute water-table change per grid square during five-year test periods with Models 1, 2 and 3. See main text for full details. Note the logarithmic scales on both axes.

developmental steps with all default parameter values (see Table 1) and $\Delta t_{\mathrm{e}}=50 \mathrm{~h}$. We then allowed the hydrological submodel to continue for a further five years of simulated time, without any further changes in the spatial distributions of micro-habitats or peat properties. For each simulated day of the five-year test we calculated the daily sum of absolute water-table movements in each model grid square, and then averaged these absolute changes for all grid squares. In all three models the average rate of water-table change declined rapidly from initial values of between 14 and $19 \mathrm{~mm} \mathrm{day}^{-1}$ to between 0.03 and $0.14 \mathrm{~mm} \mathrm{day}^{-1}$ by the end of the fiveyear test period (Fig. 2). The tests indicate that water-table behaviour for all three models converges on steady state with increasing $\Delta t_{\mathrm{e}}$.

The depth of the water table below the surface at any point in model time is given simply by

$Z=B-H$,

where $Z$ is water-table depth [L]; and $B$ is the height of the peatland surface relative to the arbitrary datum $[\mathrm{L}]$. We refer to the value of $Z$ at the end of a developmental step as $Z_{\text {final }}$; and the time-averaged value of $Z$ during the second half of a developmental step as $Z_{\text {mean }}$. These two metrics are used as inputs to the ecological submodel (Sect. 2.3).

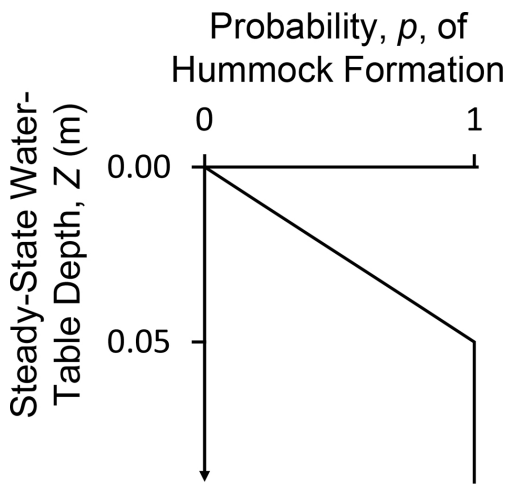

Figure 3. Graphical representation of the linear probability function used by the ecological submodel to assign hummock and hollow states to each model cell, based on water-table depth.

\subsection{Ecological submodel}

In Models 1, 2 and 3 the probability, $p$ [dimensionless], of any model cell being designated as a hummock during a given developmental step is a linear function of watertable depth, $Z_{\text {final }}$, at the end of the previous developmental step. When the water table is at the surface in any cell (i.e. when $Z_{\text {final }}=0.00 \mathrm{~m}$ ), $p=0$ (i.e. that cell is necessarily designated as a hollow for the following developmental step). The value of $p$ increases linearly with increasing water-table depth up to $Z_{\text {final }}=0.05 \mathrm{~m}$. When $Z_{\text {final }}$ is equal to or greater than $0.05 \mathrm{~m}$, the cell is automatically designated a hummock (i.e. $p=1$ ). The relevant equations (see also Fig. 3 ) are

$$
\begin{array}{lr}
p=0.0 & \text { for } Z \leq 0.00 \mathrm{~m} \\
p=20 Z & \text { for } 0.00 \mathrm{~m}<Z<0.05 \mathrm{~m} \\
p=1.0 & \text { for } Z \geq 0.05 \mathrm{~m},
\end{array}
$$

where $Z$ is equal to either final water-table depth at the end of a developmental step, $Z_{\text {final }}$ (Models 1, 2 and 3), or timeaveraged water-table depth during the second half of a twoyear developmental step, $Z_{\text {mean }}$ (Model 4) (see below).

We refer to the upper $0.05 \mathrm{~m}$ of the soil profile as the transition zone. All cells that are not designated as hummocks are automatically designated as hollows. Swanson and Grigal (1988) provide a full description of micro-habitat transitions as simulated in our Models 1, 2 and 3. In Model 4 micro-habitat transitions are dealt with slightly differently. Rather than $Z_{\text {final }}$, Model 4 assigns hummocks and hollows 
based on each grid square's time-averaged water-table depth, $Z_{\text {mean }}[\mathrm{L}]$, during the second half of the previous $2 \mathrm{yr}$ developmental step. The first 365 days of each developmental step are used to allow Model 4's simulated water tables to adjust to the newly updated distribution of peat hydraulic properties, but this adjustment period is not incorporated into $Z_{\text {mean }}$. This measure was intended to ensure that $Z_{\text {mean }}$ in Model 4 contains no meaningful artefact of water-table geometries from earlier developmental steps. Along with a variable rainfall time series (see Sect. 2.5, below) the use of $Z_{\text {mean }}$ provided a means of introducing transience to water-table behaviour in an arguably more realistic manner than the short equilibration times used in Models 1 to 3.

\subsection{Soil properties submodel}

Hummocks are assumed to produce peat that is less permeable than that produced by hollows. DigiBog's implementation of the Boussinesq equation uses depth-averaged saturated hydraulic conductivity, $K_{\text {ave }}$, and the thickness of flow, $d$, to calculate saturated groundwater flux between adjacent columns (Eq. 1). However, the original SGCJ models simply assigned a single value of transmissivity, $T_{\text {hum }}$, to hummocks and another, higher value, $T_{\text {hol }}$, to hollows. Model 1 uses the simple treatment of canonical transmissivities as per the original SGCJ models; thus, in the case of Model 1, Eq. (1) simplifies to

$$
\frac{\partial H}{\partial t}=\frac{\partial}{\partial x}\left(\frac{T}{\theta} \frac{\partial H}{\partial x}\right)+\frac{\partial}{\partial y}\left(\frac{T}{\theta} \frac{\partial H}{\partial y}\right)+\frac{U}{\theta} .
$$

We assumed default transmissivity values of $T_{\text {hol }}=2.0 \times$ $10^{-4} \mathrm{~m}^{2} \mathrm{~s}^{-1}$ and $T_{\text {hum }}=1.0 \times 10^{-5} \mathrm{~m}^{2} \mathrm{~s}^{-1}$, thereby preserving the $T_{\text {hol }}$ to $T_{\text {hum }}$ ratio of $20: 1$ that led to strong patterning in the original SGCJ models. Models 2, 3 and 4 use a more sophisticated and realistic treatment allowed by DigiBog, whereby hummocks and hollows are assigned canonical values of hydraulic conductivity, $K_{\text {hum }}$ and $K_{\text {hol }}$, respectively; $T$ for each cell is recalculated during each iteration of the hydrological submodel as the product of $K$ and the thickness of flow, $d$ (height of water table above the model's impermeable base layer) (cf. Freeze and Cherry, 1979). In this way $T$ is able to vary in a continuous manner based on water-table position, which is more realistic than the simple binary- $T$ treatment of the original SGCJ models (Eq. 1). For Models 2, 3 and 4, we assumed default values of $K_{\text {hol }}=1.0 \times 10^{-3} \mathrm{~m} \mathrm{~s}^{-1}$ and $K_{\text {hum }}=5.0 \times 10^{-5} \mathrm{~m} \mathrm{~s}^{-1}$, thereby giving a $K_{\text {hol }}$ to $K_{\text {hum }}$ ratio of $20: 1$. In models 1,2 and 3 we also manipulated the default values of $T$ or $K$ by factors of between 0.05 and 20 in line with objective (i). In Model 1 we varied $T_{\text {hum }}$ between $5.0 \times 10^{-7}$ and $2.0 \times 10^{-4} \mathrm{~m}^{2} \mathrm{~s}^{-1}$; and $T_{\text {hol }}$ between $1.0 \times 10^{-5}$ and $4.0 \times 10^{-3} \mathrm{~m}^{2} \mathrm{~s}^{-1}$, whilst always maintaining a $T_{\text {hol }}$ to $T_{\text {hum }}$ ratio of $20: 1$. Similarly, in Models 2 and 3 we varied $K_{\text {hum }}$ between $2.5 \times 10^{-6}$ and $1.0 \times 10^{-3} \mathrm{~m} \mathrm{~s}^{-1}$; and $K_{\text {hol }}$ between $5 \times 10^{-5}$ and $2 \times 10^{-2} \mathrm{~m} \mathrm{~s}^{-1}$, whilst maintaining a $K_{\text {hol }}$ to $K_{\text {hum }}$ ratio of $20: 1$.

\subsection{Model spatial and temporal domains; boundary conditions}

We implemented all simulations in a 70 (across-slope, $x$ direction) $\times 200$ (along-slope, $y$ direction) grid of $1 \mathrm{~m} \times 1 \mathrm{~m}$ grid squares. In Models 1 and 2, the simulated peat aquifer overlaid a sloping impermeable base (replicating the assumption of an impermeable lower peat layer in the SGCJ models). Both the peat surface and the impermeable base had a constant slope of $1: 50$; the permeable upper peat had a uniform thickness of $0.2 \mathrm{~m}$. In Models 3 and 4 we assumed the thick, lower peat layer is also permeable with its own hydraulic conductivity, $K_{\text {deep }}$, meaning that $K$ for each cell is depth-averaged to account for the vertical transition in $K$ between the upper and lower layers. Baird et al. (2012) provide a full description of DigiBog's calculation of $K_{\text {ave }}$ and inter-cell $T$. We used the groundwater mound equation (Ingram, 1982) to calculate the dimensions of a deep peat layer that is hemi-elliptical in cross section, has a uniform $K$ of $1.25 \times 10^{-5} \mathrm{~m} \mathrm{~s}^{-1}$, is $200 \mathrm{~m}$ from central axis to the margin, is underlain by a flat impermeable base, and receives a net water input (from an implied upper peat layer) of $155 \mathrm{~mm} \mathrm{yr}^{-1}$. The resulting deep peat layer was $3.97 \mathrm{~m}$ thick along its central axis, curving elliptically down to $0.28 \mathrm{~m}$ at the peatland's margin. Within DigiBog, this deep layer was overlain by a surficial, more permeable layer, which, like Models 1 and 2, was $0.2 \mathrm{~m}$ thick.

We allowed all simulations to run for 100 developmental steps; the initial condition consisted of randomly generated water tables, between 0.0 and $0.05 \mathrm{~m}$ below the peat surface, in each cell. The initial micro-habitat and soil-properties maps were based on this random initial water-table map in the usual manner described above.

In all simulations we set the lateral (along-slope) boundaries to impermeable (Neumann zero-flux condition) in order to simplify the representation of the simulated peatland within its local hydrogeological setting. In the simulations with an impermeable lower peat layer (Models 1 and 2) both the upslope and downslope boundaries were set to constant water-table (Dirichlet) conditions of $0.025 \mathrm{~m}$ below the surface such that the overall hydraulic gradient along the model was equal to the topographic gradient and the gradient of the impermeable peat layer. As with the original SGCJ models, Models 1 and 2 received no rainfall; all inputs of water in these models came from the upper boundary condition, representing shallow groundwater influx and/or surface runon. In this way Models 1 and 2 might be thought to be more representative of throughflow fens than of raised bogs. In Models 3 and 4 we replaced the constant-head condition at the up-slope boundary with a no-flow (Neumann zero flow) condition to represent the drainage divide along the crest of a raised bog in a manner similar to Morris et al. (2012) (see also Ingram, 1982), but retained the constant water-table condition at the lower boundary to represent shallow drainage outflow, to a lag stream, for example. Water-table levels in 


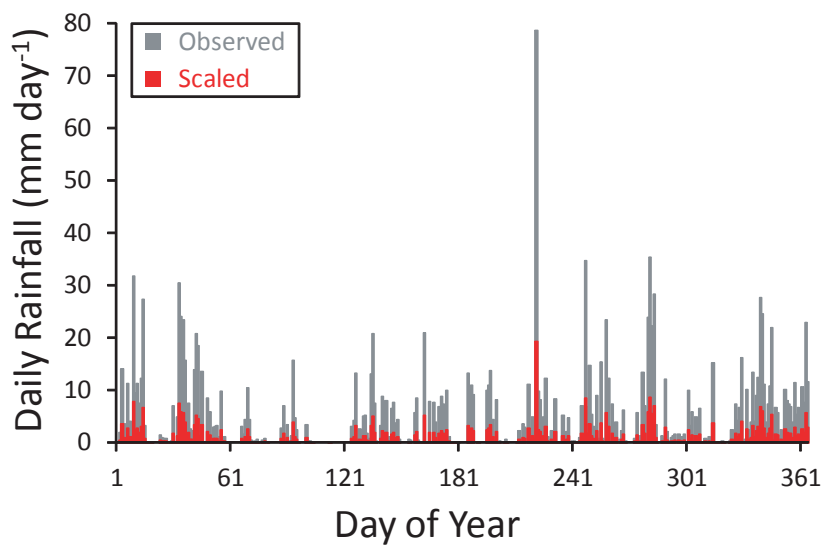

Figure 4. 365-day time series of daily observed rainfall, and its conversion to net rainfall, $U$, after scaling by a factor of 0.245 . See main text for full details.

Model 3 were maintained by a constant simulated net rainfall rate of $U=400 \mathrm{~mm} \mathrm{yr}^{-1}$ ( $U$ is assumed to be net of evapotranspiration, interception and runoff; hence, its low value). We drove Model 4 using a daily time series of $U$. We took 365 days of daily rainfall data from close to Malham Tarn Moss, a raised bog in North Yorkshire, United Kingdom, for the calendar year 2011. The rain gauge recorded precipitation on 294 days of that year, with an annual total of $1633 \mathrm{~mm}$ of precipitation. Maximum daily precipitation for the year was $78.6 \mathrm{~mm}$ on 10 August. We multiplied each daily rainfall total in the time series by approximately 0.245 so as to give an annual total of $400 \mathrm{~mm}$ of net precipitation, equal to the constant $U$ assumed in Model 3, whilst maintaining a plausible temporal variation (Fig. 4). During each $2 \mathrm{yr}$ developmental step in Model 4 we cycled twice through the 365-day rainfall series. By using the same year of rainfall data repeatedly in this way we were able to induce water-table transience without the potentially complicating effects of inter-annual variability in rainfall patterns. The thick peat deposit represented in Models 3 and 4, and the fact that their groundwater mounds were maintained by simulated net rainfall, means that they might be thought to be most representative of ombrotrophic raised bogs.

\subsection{Analysis}

Previous studies (e.g. Andreasen et al., 2001; Eppinga et al., 2009) have demonstrated that the human eye is a powerful tool for assessing pattern strength in landscape models, and we used a visual appraisal of the two-dimensional micro-habitat maps produced by the four models as our primary means of estimating simulated pattern strength. In addition we calculated the relative variance, $R$ [dimensionless], of hummocks per across-slope row of cells, following the method of Swanson and Grigal (1988), as an objective and reproducible metric of pattern strength. The value of $R$ in- creases with pattern strength: values less than 2 indicate unordered landscapes without discernible patterning; values of $R$ greater than 4 represent highly ordered landscapes with clear, strong patterning. We also calculated the proportion, $S$ [dimensionless], of model cells occupied by hummocks during each developmental step. Finally, we calculated model turnover rate, $Q$ [dimensionless], defined as the proportion of model cells that undergo a transition from hummock to hollow, or vice versa, in each developmental step.

\section{Results}

\subsection{Hydrological transience}

In Models 1, 2 and 3, the strength of across-slope, striped patterning at SL2 initially increased strongly with increasing hydrological steadiness, from an apparently entirely unordered, random mixture of hummocks and hollows at SL1 when $\Delta t_{\mathrm{e}}=1 \mathrm{~h}$, to peak "strengths" at around $\Delta t_{\mathrm{e}}=100 \mathrm{~h}$ (for Models 1 and 2) or $50 \mathrm{~h}$ (Model 3). This increase in patterning strength is evident from both a visual appraisal of the final micro-habitat maps (Fig. 5), and an increase in the values of relative variance, $R$, with increasing $\Delta t_{\mathrm{e}}$ (Fig. 6a, b, c). For values of $\Delta t_{\mathrm{e}}$ greater than $50 \mathrm{~h}$ (Models 1 and 2 ) and $20 \mathrm{~h}$ (Model 3), an increase in the spatial scale of the simulated SL2 stripes is apparent with increasing $\Delta t_{\mathrm{e}}$ (i.e. the stripes became broader in the $y$ (along-slope) direction). Increasing $\Delta t_{\mathrm{e}}$ also led to SL2 stripes whose upslope and downslope edges were increasingly straight and sharply defined (Fig. 5). For values of $\Delta t_{\mathrm{e}}$ greater than $100 \mathrm{~h}$ (Models 1 and 2) or $50 \mathrm{~h}$ (Model 3), the simulated SL2 stripes had broadened to the point of appearing to be "over-developed", such that they no longer resembled realistic peatland striped patterning (cf. Fig. 1).

As well as governing the spatial configuration of simulated patterning, the value of $\Delta t_{\mathrm{e}}$ also affected the temporal dynamics of Models 1, 2 and 3. For low values of $\Delta t_{\mathrm{e}}$, turnover rates of model cells were high: when $\Delta t_{\mathrm{e}}=1 \mathrm{~h}$, approximately half of all cells would undergo a transition from designation as a hummock to a hollow (or vice versa) during each developmental step, providing further indication of a random landscape. Increasing $\Delta t_{\mathrm{e}}$ led to a reduction in turnover rates in Models 1 and 2 as SL2 structures began to stabilise, to a minimum of approximately $40 \%$ of cells per developmental step when $\Delta t_{\mathrm{e}}=100 \mathrm{~h}$ (Fig. 6d, e). Increasing $\Delta t_{\mathrm{e}}$ had little effect on turnover rates in Model 3 until $\Delta t_{\mathrm{e}}=1000$ or $10000 \mathrm{~h}$ (Fig. 6f). The temporal trends in SL1 turnover rate and proportional hummock coverage also indicate what appears to be a limit cycle in the behaviour of all models under highly stringent hydrological steady-state criteria. Particularly when $\Delta t_{\mathrm{e}}=17520$ (Model 4 only) or $10000 \mathrm{~h}$, and to a lesser extent when $\Delta t_{\mathrm{e}}=1000 \mathrm{~h}$, the models exhibited a cyclical behaviour in time whereby the simulated landscape would alternate on an approximately regular cycle of between four and ten developmental steps between two contrasting states: 

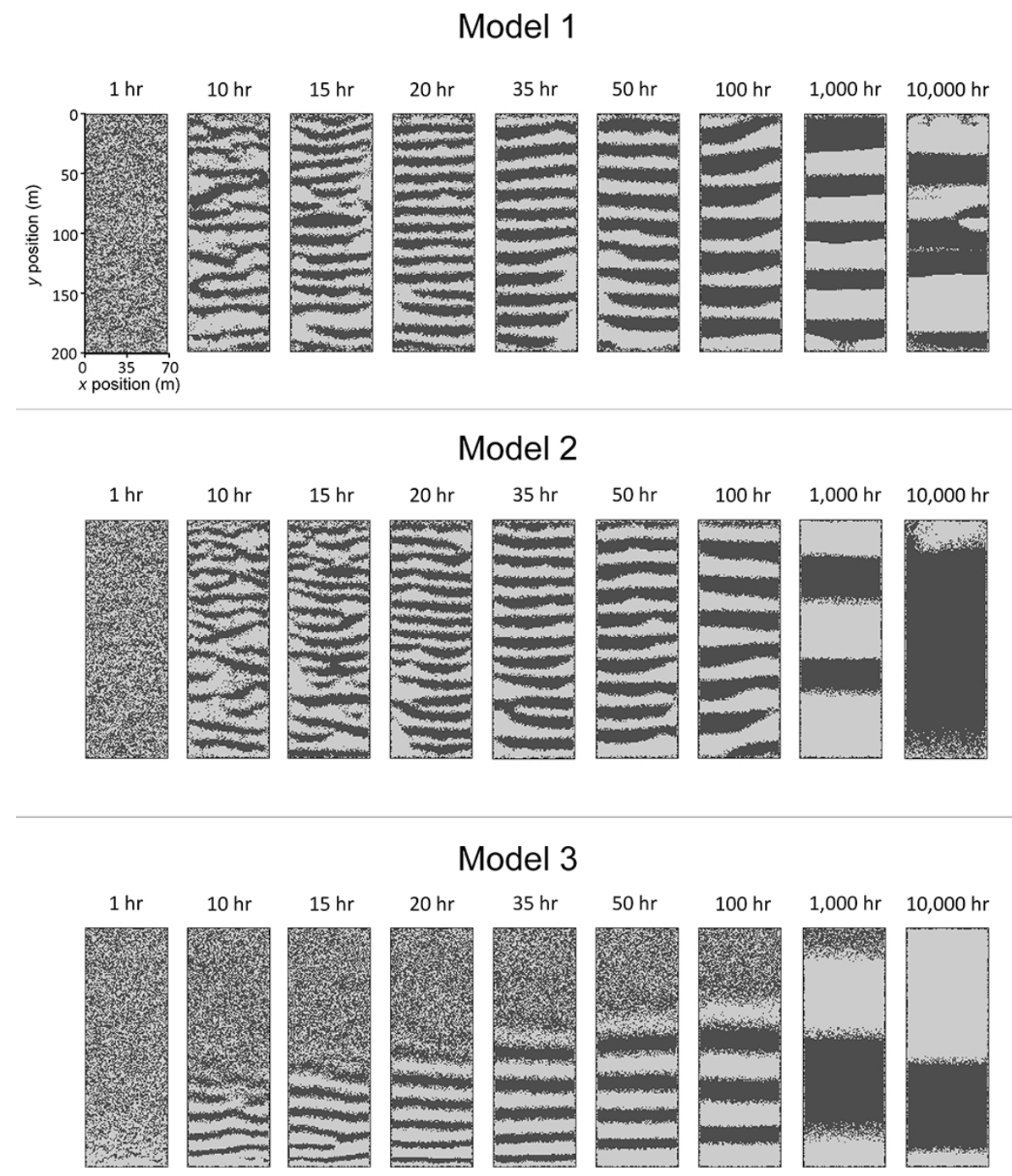

Figure 5. Final micro-habitat maps after 100 developmental steps, showing effects of increasing $\Delta t_{\mathrm{e}}$ on patterning in typical simulations with Model 1 (top panel), Model 2 (middle panel) and Model 3 (bottom panel). The value of $\Delta t_{\mathrm{e}}$ assumed for each simulation is indicated immediately above the map. Light pixels represent hummocks, dark pixels represent hollows. Low values of $y$ represent upslope locations ( $y=0$ is the upslope boundary); high values of $y$ represent downslope locations ( $y=200$ is the downslope boundary); as such, groundwater flow is generally down the page. All maps have the same horizontal $(x, y)$ scale as that shown for the upper-leftmost map.

a dry landscape with deeper water tables, dominated by hummocks; and a wet landscape with water tables near the bog surface, dominated by hollows (Fig. 6). The contrast between the wet and dry states was particularly pronounced in Model 2, which cycled between approximately $15 \%$ and $95 \%$ hummock coverage when $\Delta t_{\mathrm{e}}=10000 \mathrm{~h}$ (Fig. 6h). The single simulation with Model $4\left(\Delta t_{\mathrm{e}}=17520 \mathrm{~h}\right)$ behaved in a very similar manner to Models 1,2 and 3 when $\Delta t_{\mathrm{e}}=$ $10000 \mathrm{~h}$, predicting nearly homogeneous, unpatterned landscapes (Fig. 7) that cycled rapidly between being dominated by hummocks and hollows (Fig. 6f, i).

In all simulations that generated striped SL2 patterning, those SL2 units migrated consistently downslope (not shown) in the same manner as that previously reported in the published accounts of the SGCJ models.

\subsection{Simplified calculation of transmissivity}

Any artefacts introduced to model behaviour by the simple, binary treatment of peat permeability employed in the original SGCJ models (see objective i, above) would have been evident as differences in behaviour between Model 1 (simple, binary transmissivity scheme, based solely on hummock/hollow designation) and Model 2 (continuous treatment of transmissivity as product of peat hydraulic conductivity and thickness of flow). Models 1 and 2 behaved in a very similar manner to one another, in terms of their response 
Model 1

a)

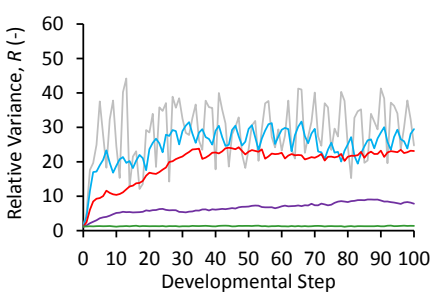

d)

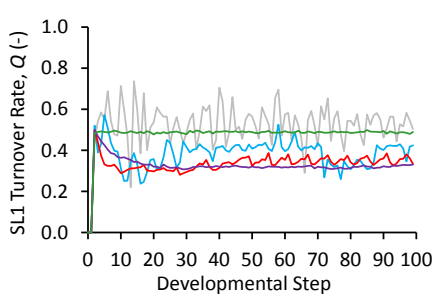

g)

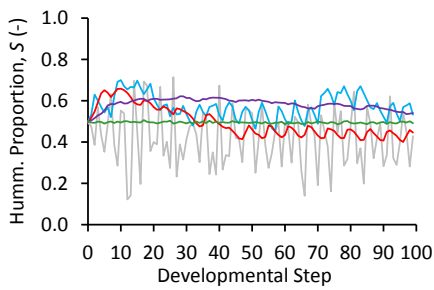

Model 2

b)

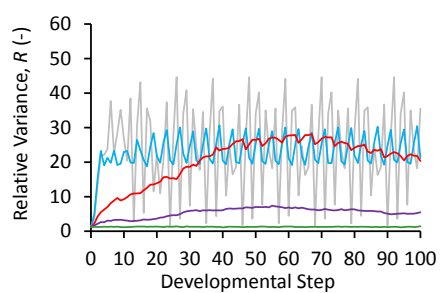

e)

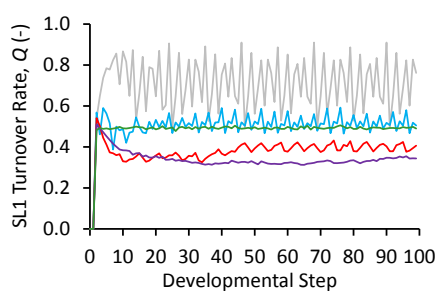

h)

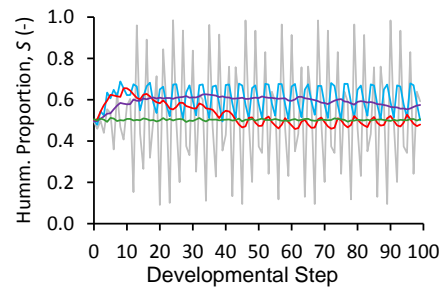

Models 3 and 4

c)

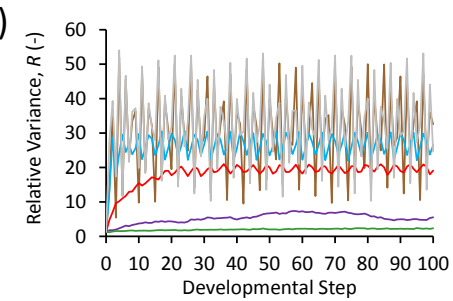

f)

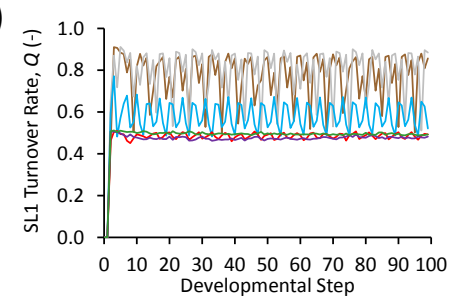

i)

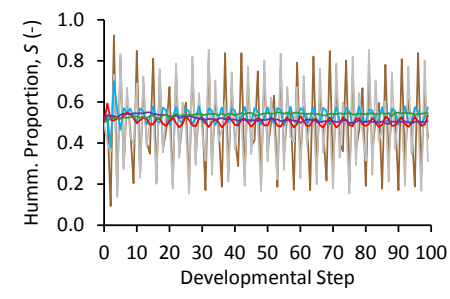

\begin{tabular}{|c|c|c|c|c|c|}
\hline \multicolumn{6}{|c|}{$\Delta t_{\mathrm{e}}$} \\
\hline$-1 \mathrm{hr}$ & $-10 \mathrm{hr}$ & $-100 \mathrm{hr}$ & $-1,000 \mathrm{hr}$ & $-10,000 \mathrm{hr}$ & $-17,520 \mathrm{hr}$ (Model 4 only) \\
\hline
\end{tabular}

Figure 6. Influence of hydrological equilibration time, $\Delta t_{\mathrm{e}}$, over temporal development of relative variance of hummocks per model row, $R$ (top row); SL1 turnover rate, $Q$ (middle row); and proportion of model landscape occupied by hummocks, $S$ (bottom row); in Models 1 (left column), 2 (middle column), 3 and 4 (right column).

to both changing values of $\Delta t_{\mathrm{e}}$ and changing absolute values of peat permeability. Both models developed realistic looking, contour-parallel SL2 stripes over the entire model domain for intermediate values of $\Delta t_{\mathrm{e}}$. In both models the striped patterning was relatively weak and discontinuous for $\Delta t_{\mathrm{e}}=15$ and $20 \mathrm{~h}$; the patterns were stronger and continuous when $\Delta t_{\mathrm{e}}$ was between 35 and $100 \mathrm{~h}$; the SL2 stripes became unrealistically broad at $\Delta t_{\mathrm{e}}=1000 \mathrm{~h}$, and were mainly absent when $\Delta t_{\mathrm{e}}=10000 \mathrm{~h}$ (Fig. 5). Temporal patterns of summary metrics (SL1 turnover rate, hummock proportion, relative variance of hummocks per row) were qualitatively and quantitatively similar between models 1 and 2, and again responded similarly to changes in $\Delta t_{\mathrm{e}}$ (Fig. 6) and the ratio of $T_{\text {hum }}$ to $T_{\text {hol }}$ or $K_{\text {hum }}$ to $K_{\text {hol }}$ (not shown).

\subsection{Hydrogeological setting}

Any artefacts introduced to model behaviour by the simplifying assumptions made in the original SGCJ models about the hydrogeological setting of the simulated peatland (see objective ii, above) would have been evident as differences in behaviour between Model 2 (impermeable deep peat layer; constant-head upslope boundary condition; zero rainfall addition; constant slope of peatland surface) and Model 3 (permeable deep peat layer; no-flow upslope boundary; constant net rainfall rate of $400 \mathrm{~mm} \mathrm{yr}^{-1}$; hemi-elliptical aquifer shape). Model 2 simulations that generated patterning did so over the entire model domain, although the same was not true of Model 3. Striped patterning at SL2 developed in Model 3 only in the downslope portion of the model domain. Furthermore, the area of the model domain that exhibited patterning extended upslope with increasing values of $\Delta t_{\mathrm{e}}$. For instance, when $\Delta t_{\mathrm{e}}=10 \mathrm{~h}$, Model 3 only produced striped patterning within $60 \mathrm{~m}$ or so of the downslope boundary, but when $\Delta t_{\mathrm{e}}=100 \mathrm{~h}$ the patterned area covered the majority of the model domain and extended as far as approximately $140 \mathrm{~m}$ from the downslope boundary (Fig. 5). Clear, continuous striped patterning that extended all the way across the across-slope direction ( $x$ direction) of the model domain developed in Model 3 at much lower values of $\Delta t_{\mathrm{e}}$ than in Model 2. Continuous, closely spaced SL2 stripes were evident in the downslope area of Model 3 when $\Delta t_{\mathrm{e}}=20 \mathrm{~h}$, 


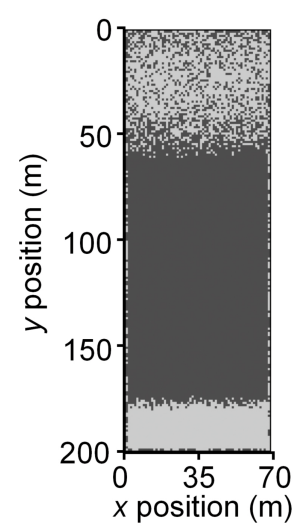

Figure 7. Final micro-habitat map after 100 developmental steps from Model 4, with $\Delta t_{\mathrm{e}}=17520 \mathrm{~h}$ (2 yr). Light pixels represent hummocks, dark pixels represent hollows. Low values of $y$ represent upslope locations ( $y=0$ is the upslope boundary); high values of $y$ represent downslope locations ( $y=200$ is the downslope boundary); as such, groundwater flow is generally down the page.

although sharply defined, continuous SL2 stripes in Model 2 did not develop for values of $\Delta t_{\mathrm{e}}$ less than $35 \mathrm{~h}$. Additionally, Model 3 behaved differently from Model 2 in terms of its responses to changes in the absolute values of peat hydraulic conductivity (see below).

\subsection{Manipulation of peat properties}

Modest changes in the absolute values of $T$ or $K$ brought about large changes in the nature and strength of simulated patterning in Models 1, 2 and 3, although the nature of these responses varied between models. In Models 1 and 2, the lowest values of $T$ or $K$ led to largely unpatterned landscapes, dominated by apparently random distributions of hummocks and hollows, with either a complete absence of patterning $(\times 0.05$ treatment $)$ or very weak, discontinuous patterning ( $\times 0.1$ treatment) (Fig. 8). In both Models 1 and 2, pattern strength increased with increasing values of $T$ or $K$ up to the default combination. For combinations of $T$ and $K$ greater than the default values, Models 1 and 2 both predicted an increase in the spatial scale of SL2 stripes in a manner similar to the effect of increasing $\Delta t_{\mathrm{e}}$; for the $\times 10$ and $\times 20$ treatments Model 1 became almost a uniform landscape of hummocks with only small SL2 groupings of hollows. The behaviour of Model 3 was quite different. Only the default and the $\times 0.2$ treatments generated any kind of contour-parallel stripes; all other treatments produced near-uniform, unpatterned landscapes composed almost entirely of either hollows (for the $\times 0.05$ and $\times 0.1$ treatments) or hummocks (for the $\times 5, \times 10$ and $\times 20$ treatments).
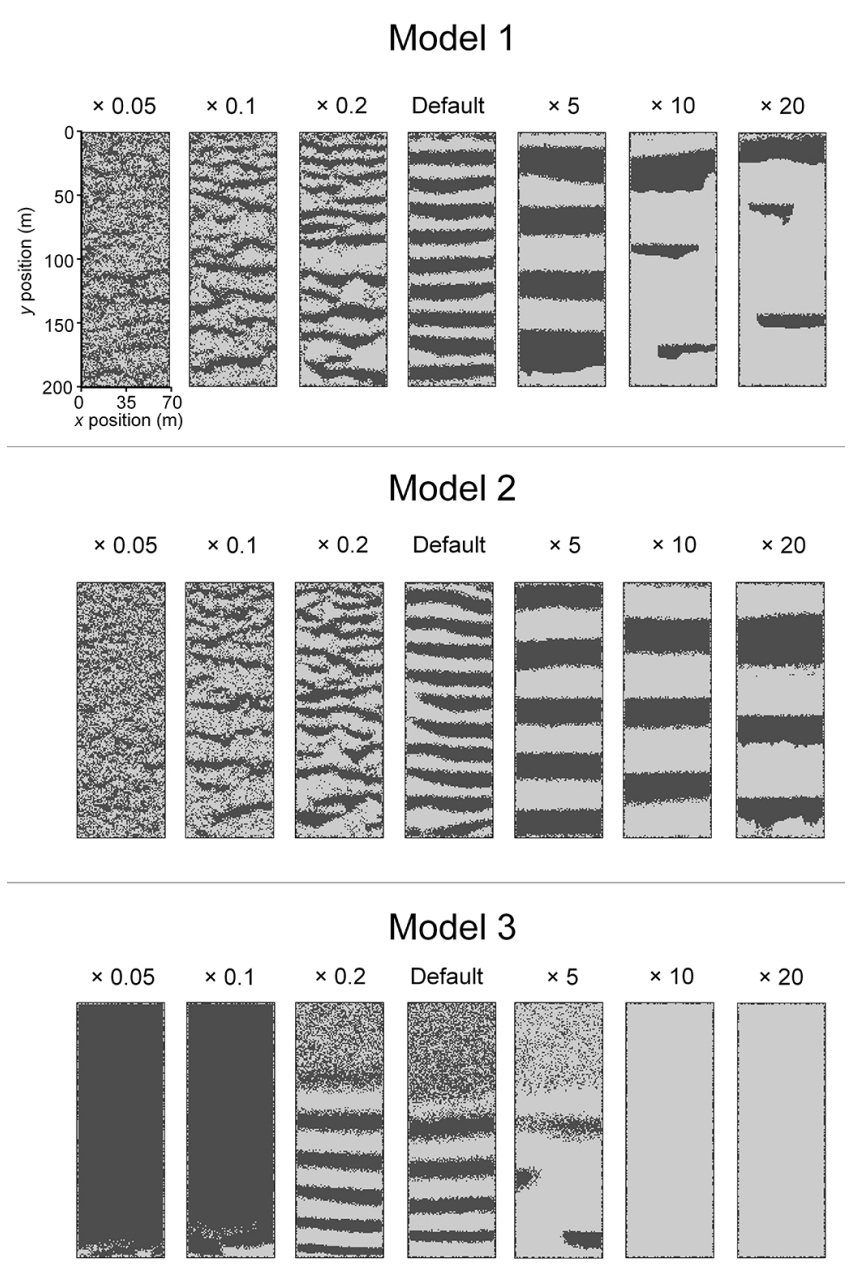

Figure 8. Final micro-habitat maps after 100 developmental steps, showing effects of different combinations of $T_{\text {hum }}$ and $T_{\text {hol }}$ (in the case of Model 1, top panel) or $K_{\text {hum }}$ and $K_{\text {hol }}$ (Model 2, middle panel; Model 3, bottom panel) on pattern geometries in typical model runs. The values of $T$ or $K$ used in each simulation are indicated immediately above the maps, and are expressed as a factor of the default values. See main text for full explanation. Light pixels represent hummocks, dark pixels represent hollows. Low values of $y$ represent upslope locations ( $y=0$ is the upslope boundary); high values of $y$ represent downslope locations ( $y=200$ is the downslope boundary); as such, groundwater flow is generally down the page. All maps have the same horizontal $(x, y)$ scale as that shown for the upper-leftmost map.

\section{Discussion}

\subsection{Hydrological transience and ecological memory}

The striking similarity between the patterns generated by our Models 1,2 and 3 at intermediate values of $\Delta t_{\mathrm{e}}$ and the striped patterns reported by the previous SGCJ authors, as well as the absence of patterning in our models under more stringent steady-state hydrological conditions, are highly suggestive that the simulations reported in the previous SGCJ 
studies had not attained genuine steady-state hydrological conditions. The dependence of realistic patterning in our models on intermediate equilibration times can be reconciled with the currently popular theory that landscape patterning commonly arises from interplay between long- and shortrange processes (e.g. Rietkerk and van de Koppel, 2008; see also Turing, 1952). The strength of the long-range negative feedback (which acts to homogenise local differences in water-table position in response to distant hydrological boundary conditions) appears to increase as the hydrological equilibration time is lengthened. When equilibration times are very short each grid square's water-table behaviour is influenced only by its immediate neighbours, and long-range influences are unable to propagate across the model domain. Conversely, the longest equilibration times cause the simulated water-table map to be dominated by its long-range boundary conditions, which, under steady state, eliminate much of the short-range effects of contrasting peat hydraulic properties in neighbouring SL1 and SL2 units. Without additional feedbacks such as those explored by Eppinga et al. (2009), it is only at intermediate values of $\Delta t_{\mathrm{e}}$ that the model strikes the balance of long- and short-range feedbacks seemingly required for patterning.

If the absolute values of $\Delta t_{\mathrm{e}}$ are taken literally then the model predicts that realistic patterning only occurs if microsuccession at SL1 operates on unrealistically short timescales of hours to days, rather than years. Moreover, Model 4, in which we introduced water-table transience not through short equilibration times but through a daily rainfall series, did not generate patterning. This indicates clearly that it is the short equilibration times used in Models 1, 2 and 3, rather than simply non-steady water tables (which are also present in Model 4) that caused patterning in our simulations. It is perhaps initially tempting to discard the model in light of its reliance on hydrological transience.

However, an alternative and more abstract interpretation of the models' dynamics allows one to conceptualise the length of a developmental step simply as a measure of hydrological steadiness under which succession takes place. With this in mind, we can think of succession as occurring over a period of years, during which the degree of hydrological steadiness is determined by $\Delta t_{\mathrm{e}}$. Therefore, $\Delta t_{\mathrm{e}}$ is no longer a literal time period during which plant community succession occurs but merely a means of representing hydrological steadiness. For lower values of $\Delta t_{\mathrm{e}}$, the water tables across the models' domains are not in full equilibrium with the current distribution of hummocks and hollows. As such, those water-table maps reflect the distribution of hummocks and hollows during not only the current developmental step but also partly the previous developmental step. It may be that the formation of peatland patterning relies on some ecological memory effect (cf. Peterson, 2002), such as the influence of recently buried peat that no longer reflects current positions of hummocks and hollows but which remains hydrologically important due to its shallow depth. Despite Digi-
Bog allowing for 3-dimensional variation in peat properties, the ponding model is in essence a 2-dimensional model insofar as the new micro-habitat map during each developmental step supersedes the previous map entirely; the modelled system retains no memory of previous SL1 units or their associated soil properties. As such, our models neglect some of the structural complexity that peatlands exhibit in three spatial dimensions (e.g. Barber, 1981). Our simulations with nonconservative hydrological steady-state criteria (particularly $\Delta t_{\mathrm{e}}=50$ and $100 \mathrm{~h}$ ) implicitly contain a type of ecological memory effect, because the influence of previous patterns of surface vegetation and shallow soil properties are expressed in the model's hydrological behaviour; this memory effect decreases in strength with increasingly stringent hydrological steady-state criteria. Our results indicate that this memory effect is important to the formation of patterning in the ponding model and should be investigated directly in future studies, perhaps via the use of cohort-based peat accumulation models (e.g. Frolking et al., 2010; Morris et al., 2011, 2012).

\subsection{Peat hydraulic properties}

Models 1, 2 and 3 were all highly sensitive to the absolute values of $T$ or $K$, and patterning only occurred within a narrow region of parameter space. Even in the $\times 0.05$ and $\times 20$ treatments, the values of $T$ or $K$ were well within reported ranges; the fact that these parameterisations failed to produce patterning suggests that a full suite of relevant processes and feedbacks has not been represented. Particularly in Model 3, in which model water-table levels are maintained by the simulated addition of rainfall, even modest changes in the absolute values of $K_{\text {hol }}$ and $K_{\text {hum }}$ caused simulations to "run away" to either wet or dry end-member states. In simulations with higher values of hydraulic conductivity Model 3 drained rapidly to the downslope boundary, causing water tables to fall below the transition zone and giving rise to uniformly dry simulated landscapes dominated by hummocks. Conversely, the simulations with lower values of hydraulic conductivity caused Model 3 to drain so slowly that water tables rose to the surface of all columns, leading to uniformly wet landscapes dominated by hollows. The same effect was not evident in Models 1 and 2 because the constanthead condition at the upslope boundary maintained watertable levels within the transition zone. Nonetheless, manipulating $T$ and $K$ in Models 1 and 2, respectively, still resulted in landscapes devoid of realistic patterning by strengthening the long-range negative feedback relative to the short-range positive feedback.

The high sensitivity to the absolute values of $T$ and $K$ may be taken to suggest that our models are lacking at least one important negative feedback, namely that between peat decomposition and changes in peat hydraulic properties. For example, saturated hydraulic conductivity is known to decrease strongly with increasing time-integrated 
decomposition of peat (e.g. Boelter, 1969; 1972; Grover and Baldock, 2013). Areas with deep water tables are prone to more rapid decomposition and more rapid collapse of pore spaces. The resultant reduction in hydraulic conductivity in turn causes peat to retain water more readily and causes decay rates to fall, stabilising system behaviour (see Belyea, 2009; and Morris et al., 2012). This concept is partially represented in the ponding model by lower values of $T$ or $K$ in hummocks (where peat spends more time under oxic conditions, and hence peat at the water table is more degraded and less permeable) than in hollows (where peat has a shorter residence time under oxic conditions, producing better-preserved and more permeable peat at the depth of the water table). However, in the ponding model only two $K$ values are possible, $K_{\text {hum }}$ and $K_{\text {hol }}$, meaning that hydraulic conductivity cannot vary as a continuous function of decomposition; the ponding model's representation of this relationship may therefore be overly constrained. Modelling studies by Morris et al. (2011) and Swindles et al. (2012) have indicated that a continuous relationship between peat decomposition and hydraulic conductivity may be highly important to the ability of peatlands to self-organise and to maintain homeostatic water-table behaviour. The representation of this negative feedback within models of peatland patterning such as ours has the potential to stabilise model behaviour by allowing simulated water tables and peat permeability to self-organise, thereby reducing model sensitivity to small changes in soil hydraulic parameter values. This would require the expansion of the ponding model so as to include routines that describe litter production and decomposition, and continuous changes in peat hydraulic conductivity. The inclusion of these processes in patterning models would also help to address the question raised above of ecological memory effects, and suggests the need to unify models of peatland surface patterning such as those considered here, and cohort models of long-term peatland development (e.g. Frolking et al., 2010; Morris et al., 2011, 2012).

\subsection{Improved model hydrology}

Our alterations to the ponding model's hydrological basis compared to previously published versions had little impact on model behaviour, evidenced by the fact that Models 1, 2 and 3 all behaved in qualitatively similar manners, including their response to hydrological transience. The previous SGCJ authors reported that patterning is stronger and forms more readily as the slope angle of the model domain, and associated hydraulic gradients, are increased. The curved crosssectional shape of the bog in Model 3 means that slope angle near the downslope boundary is greater than the uniform $1: 50$ slope in Models 1 and 2. This appears to have allowed weak striping to develop at the downslope end of Model 3 even under hydrological conditions that were so transient as to prevent patterning in Models 1 and 2. Increasing hydrological steadiness in Model 3 then allowed patterning to spread upslope onto increasingly shallow slopes. The differences in behaviour between Models 2 and 3 can therefore be explained by the curved aquifer shape, reflecting the slope angle effect reported by previous authors. In particular, the nature of SL2 patterning in Model 3 (Fig. 5) is strikingly similar to that seen in the simulations with domed aquifers reported by Couwenberg and Joosen (2005). We are therefore left to deduce that the permeable deep peat layer in Model 3 had little independent effect, and that the generation of patterning by the ponding mechanism is not dependent on either hydrological interaction with, or isolation from, deeper peat layers.

The simple binary treatment of hummock and hollow transmissivity used in the earlier SGCJ studies also appears to have produced no artefact in the behaviour of those models (or in our Model 1) compared to our more realistic Boussinesq treatment (in Models 2 and 3). Nonetheless, it is important to recognise that neither the simplified treatment of transmissivity nor the assumption of an impermeable deep peat layer, despite both being questionable assumptions in themselves, were responsible for the model's reliance on the hydrological steady-state criterion and the absolute values of peat hydraulic properties, nor the prediction of downslope migration of SL2 stripes. As such we are confident that these behaviours (reliance on hydrological transience; high sensitivity to absolute values of transmissivity; downslope pattern migration) are genuine facets of the ponding model and are not artefacts of numerical implementation.

\subsection{Pattern migration}

The downslope movement of SL2 stripes in the ponding model is an emergent behaviour that should be treated as a testable hypothesis against which the ponding model could, in part, be tested (cf. Grimm et al., 2005). We are aware of very little direct evidence as to the long-term stationarity or otherwise of peatland patterning, likely because the long timescales involved preclude direct observation. Koutaniemi (1999) found that SL2 units in a Finnish aapa mire expanded and contracted on a seasonal basis due to frost heave, but he saw no evidence of consistent downslope migration of any of these features over a $21 \mathrm{yr}$ period. Foster and Wright (1990) analysed the age of pool-bottom sediments from a Swedish raised bog. They also found no evidence of migration over thousands of years. Rather, they concluded that the age of pools was determined largely by the timing of the lateral expansion of the bog, and that once formed the pools remained stationary. However, Kettridge et al. (2012) used data from a combination of ground-penetrating radar and soil cores to investigate the below-ground physical properties of peat soil in a raised bog in Wales. They found subsurface layers that dipped consistently towards the bog's margins, which they interpreted as evidence of down-slope migration of SL1 or SL2 units during the bog's development. More observational work is clearly required to ascertain whether or not 
the findings of Kettridge et al. (2012) hold in the general case, but it appears that the ponding model's prediction of the downslope migration of SL2 stripes cannot be used to falsify the model at this stage.

\section{Summary and conclusions}

Our numerical experiments suggest strongly that simulations reported in previous studies had not attained true hydrological steady-state conditions; under true steady state patterning does not occur. Realistic, striped patterns only form when micro-habitat transitions occur in response to highly transient water-table patterns. The equilibration times required by the hydrological submodel to attain the level of transience necessary for patterning are of the order of hours to days: these timescales are largely meaningless in terms of vegetation dynamics. The models' reliance on the hydrological steady-state criterion indicates that ecological memory may play a role in pattern formation. Although ecological memory is not represented explicitly (or deliberately) in our models, the transient water tables appear to have inadvertently replicated such an effect.

We increased incrementally the sophistication of the models' numerical implementation and the realism of their conceptual bases, chiefly by representing a permeable deep peat layer; improving the models' calculation of transmissivity; and introducing a plausible temporal variation in rainfall. In doing so we removed a number of simplifying assumptions made in previous studies. However, these improvements had little effect on the models' behaviours, indicating that the sensitivity to hydrological steady state is a genuine facet of the models and is not an artefact of numerical implementation.

The models appear to be unrealistically sensitive to the absolute values of the parameters used to represent peat permeability. We interpret this sensitivity as indicating that the models are missing a negative feedback between peat decomposition and hydraulic conductivity, which previous studies have shown is important to the ability of peatlands to selforganise.

Peatland structures and processes exhibit complexity in three spatial dimensions. A logical next step for patterning research would be to combine 2-dimensional (horizontal only) cellular landscape models such as those presented here with (mostly 1-dimensional; vertical only) peatland development models that provide a more detailed and realistic representation of peat formation, decomposition and dynamic changes in soil hydraulic properties. This would allow a direct process-based exploration of both the mechanism involved in ecological memory, and a continuous relationship between peat decomposition and hydraulic properties.
Acknowledgements. This research was funded in part by a Queen Mary University of London PhD studentship awarded to Paul Morris. We are grateful to Brian Branfireun (University of Western Ontario) for permission to use the photograph in Fig. 1, and to The Field Studies Council at Malham, in particular Robin Sutton, for providing us with the data from Malham Tarn Weather Station. We are grateful to the associate editor for helpful dialogue, and to three referees for insightful and constructuive comments on an earlier version of the manuscript.

Edited by: F. Metivier

\section{References}

Aber, J. S., Aaviskoo, K., Karofeld, E., and Aber, S. W.: Patterns in Estonian bogs as depicted in color kite aerial photographs, Suo, 53, 1-15, 2002.

Alm, J., Talanov, A., Saarnio, S., Silvola, J., Ikkonen, E., Aaltonen, H., Nykänen, H., and Martikainen, P. J.: Reconstruction of the carbon balance for microsites in a boreal oligotrophic pine fen, Finland, Oecologia, 110, 423-431, doi:10.1007/s004420050177, 1997.

Andreasen, J. K., O’Neill, R. V., Noss, R., and Slosser, N. C.: Considerations for the development of a terrestrial index of ecological integrity, Ecol. Indic., 1, 21-35, doi:10.1016/S1470160X(01)00007-3, 2001.

Baird, A. J., Belyea, L. R., and Morris, P. J.: Upscaling of peatlandatmosphere fluxes of methane: small-scale heterogeneity in process rates and the pitfalls of "bucket-and-slab" models, in: Carbon Cycling in Northern Peatlands, Geophysical Monograph Series, 184, edited by: Baird, A. J., Belyea, L. R., Comas, X., Reeve, A., and Slater, L., American Geophysical Union, Washington, DC, 37-53, doi:10.1029/2008GM000826, 2009.

Baird, A. J., Morris, P. J., and Belyea, L. R.: The DigiBog peatland development model 1: Rationale, conceptual model, and hydrological basis, Ecohydrology, 5, 242-255, doi:10.1002/eco.230, 2012.

Barber, K. E.: Peat Stratigraphy and Climate Change: A Palaeoecological Test of the Theory of Cyclic Peat Bog Regeneration, Balkema, Rotterdam, Netherlands, 1981.

Belyea, L. R.: Nonlinear dynamics of peatlands and potential feedbacks on the climate system, in: Carbon Cycling in Northern Peatlands, Geophysical Monograph Series, 184, edited by: Baird, A. J., Belyea, L. R., Comas, X., Reeve, A., and Slater, L., American Geophysical Union, Washington, DC, 5-18, doi:10.1029/2008GM000829, 2009.

Belyea, L. R. and Baird, A. J.: Beyond "the limits to peat bog growth": Cross-scale feedback in peatland development, Ecol. Monogr., 76, 299-322, doi:10.1890/00129615(2006)076[0299:BTLTPB]2.0.CO;2, 2006.

Belyea, L. R. and Clymo, R. S.: Feedback control of the rate of peat formation, P. Roy. Soc. Lond. B, 268, 1315-1321, doi:10.1098/rspb.2001.1665, 2001.

Boelter, D. H.: Physical properties of peats as related to degree of decomposition, Soil Sci. Soc. Am. Pro., 33, 606-609, 1969.

Boelter, D. H.: Methods for analysing the hydrological characteristics of organic soils in marsh-ridden areas, in: Proceedings of the IAHS Symposium on the Hydrology of Marsh Ridden Areas, Minsk, IAHS/UNESCO, Paris, 161-169, 1972. 
Bubier, J., Costello, A., Moore, T. R., Roulet, N. T., and Savage, K.: Microtopography and methane flux in boreal peatlands, northern Ontario, Canada, Can. J. Botany, 71, 1056-1063, doi:10.1139/b93-122, 1993.

Bubier, J. L., Moore, T. R., Bellisario, L., Comer, N. T., and Grill, P. M.: Ecological controls on methane emissions from a northern peatland complex in the zone of discontinuous permafrost, Manitoba, Canada, Global Biogeochem. Cy., 9, 455470, doi:10.1029/95GB02379, 1995.

Clymo, R. S.: Hydraulic conductivity of peat at Ellergower Moss, Scotland, Hydrol. Process., 18, 261-274, doi:10.1002/hyp.1374, 2004

Comas, X., Slater, L., and Reeve, A.: Stratigraphic controls on pool formation in a domed bog inferred from ground penetrating radar (GPR), J. Hydrol., 315, 40-51, doi:10.1016/j.jhydrol.2005.04.020, 2005.

Couwenberg, J.: A simulation model of mire patterning revisited, Ecography, 28, 653-661, doi:10.1111/j.2005.09067590.04265.x, 2005

Couwenberg, J. and Joosten, H.: Self-organization in raised bog patterning: the origin of microtope zonation and mesotope diversity, J. Ecol., 93, 1238-1248, doi:10.1111/j.1365-2745.2005.01035.x, 2005.

Eppinga, M. B., Rietkerk, M., Borren, W., Lapshina, E. D., Bleuten, W., and Wassen, M. J.: Regular surface patterning of peatlands: Confronting theory with field data, Ecosystems, 11, 520-536, doi:10.1007/s10021-008-9138-z, 2008.

Eppinga, M. B., de Ruiter, P. C., Wassen, M. J., and Rietkerk, M.: Nutrients and hydrology indicate the driving mechanisms of peatland surface patterning, The American Naturalist, 173, 803818, doi:10.1086/598487, 2009.

Foster, D. R. and Fritz, S. C.: Mire development, pool formation and landscape processes on patterned fens in Dalarna, central Sweden, J. Ecol., 75, 409-437, doi:10.2307/2260426, 1987.

Foster, D. R. and Wright, H. E.: Role of Ecosystem Development and Climate Change in Bog Formation in Central Sweden, Ecology, 71, 450-463, doi:10.2307/1940300, 1990.

Fraser, C. J. D., Roulet, N. T., and Laffleur, M.: Groundwater flow patterns in a large peatland, J. Hydrol., 246, 142-154, doi:10.1016/S0022-1694(01)00362-6, 2001.

Freeze, R. A. and Cherry, J. A.: Groundwater. Prentice Hall, Englewood Cliffs, New Jersey, United States, 1979.

Frolking, S., Roulet, N. T., Tuittila, E., Bubier, J. L., Quillet, A., Talbot, J., and Richard, P. J. H.: A new model of Holocene peatland net primary production, decomposition, water balance, and peat accumulation, Earth Syst. Dynam., 1, 1-21, doi:10.5194/esd-11-2010, 2010.

Grimm, V., Revilla, E., Berger, U., Jeltsch, F., Mooij, W. M., Railsback, S. F., Thulke, H., Weiner, J., Wiegand, T., and DeAngelis, D. L.: Pattern-oriented modeling of agent-based complex systems: lessons from ecology, Science, 310, 987-991, doi:10.1126/science.1116681, 2005.

Grover, S. P. P. and Baldock, J. A.: The link between peat hydrology and decomposition: Beyond von Post, J. Hydrol., 479, 130-138, doi:10.1016/j.jhydrol.2012.11.049, 2013.

Ingram, H. A. P.: Size and shape in raised mire ecosystems: a geophysical model, Nature, 297, 300-303, doi:10.1038/297300a0, 1982.
Ivanov, K. E.: Water Movement in Mirelands (translated from Russian by Thompson, A. and Ingram, H. A. P.), Academic Press, London, 1981.

Kettridge, N., Binley, A., Comas, X., Cassidy, N. J., Baird, A. J., Harris, A., van der Kruk, J., Strack, M., Milner, A. M., and Waddington, J. M.: Do peatland microforms move through time? Examining the developmental history of a patterned peatland using ground-penetrating radar, J. Geophys. Res., 117, G03030, doi:10.1029/2011JG001876, 2012.

Korpela, I., Koskinen, M., Vasander, H., Hopolainen, M., and Minkkinen, K.: Airborne small-footprint discrete-return LiDAR data in the assessment of boreal mire surface patterns, vegetation, and habitats, Forest Ecol. Manag., 258, 1549-1566, doi:10.1016/j.foreco.2009.07.007, 2009.

Koutaniemi, L.: Twenty-one years of string movements on the Liippasuo aapa mire, Finland, Boreas, 28, 521-530, doi:10.1111/j.1502-3885.1999.tb00238.x, 1999.

Lefever, R. and Lejeune, O.: On the origin of tiger bush, B. Math. Biol., 59, 263-294, doi:10.1007/BF02462004, 1997.

McWhorter, D. B. and Sunada, D. K.: Ground-water Hydrology and Hydraulics. Water Resources Publications, Fort Collins, Colorado, United States, 1977.

Morris, P. J., Belyea, L. R., and Baird, A. J.: Ecohydrological feedbacks in peatland development: A theoretical modelling study, J. Ecol., 99, 1190-1201, doi:10.1111/j.1365-2745.2011.01842.x, 2011.

Morris, P. J., Baird, A. J., and Belyea, L. R.: The DigiBog peatland development model 2: Ecohydrological simulations in 2D, Ecohydrology, 5, 256-268, doi:10.1002/eco.229, 2012.

Nungesser, M. K.: Modelling microtopography in boreal peatlands: Hummocks and hollows, Ecol. Model., 165, 175-207, doi:10.1016/S0304-3800(03)00067-X, 2003.

Peterson, G. D.: Contagious disturbance, ecological memory, and the emergence of landscape pattern, Ecosystems, 5, 329-338, doi:10.1007/s10021-001-0077-1, 2002.

Rietkerk, M. G. and van de Koppel, J.: Regular pattern formation in real ecosystems, Trends Ecol. Evol., 23, 169-175, doi:10.1016/j.tree.2007.10.013, 2008.

Rietkerk, M. G., Dekker, S. C., de Ruiter, P. C., and van de Koppel, J.: Self-organized patchiness and catastrophic shifts in ecosystems, Science, 305, 1926-1929, doi:10.1126/science.1101867, 2004a.

Rietkerk, M. G., Dekker, S. C., Wassen, M. J., and Verkroost, A. W. M.: A putative mechanism for Bog Patterning, The American Naturalist, 163, 699-708, doi:10.1086/383065, 2004b.

Roulet, N. T., Lafleur, P. M., Richard, P. J. H., Moore, T. R., Humphreys, E. R., and Bubier, J.: Contemporary carbon balance and late Holocene carbon accumulation in a northern peatland, Glob. Change Biol., 13, 397-411, doi:10.1111/j.13652486.2006.01292.x, 2007.

Rydin, H. and Jeglum, J. K.: The Biology of Peatlands, Oxford University Press, Oxford, UK, 2006.

Swindles, G. T., Morris, P. J., Baird, A. J., Blaauw, M., and Plunkett, G.: Ecohydrological feedbacks confound peat-based climate reconstructions, Geophys. Res. Lett., 39, L11401, doi:10.1029/2012GL051500, 2012.

Swanson, D. K. and Grigal, D. F.: A simulation model of mire patterning, Oikos, 53, 309-314, 1988. 
Swanson, D. K.: Interaction of mire microtopography, water supply, and peat accumulation in boreal mires, Suo, 58, 37-47, 2007.

Turing, A.: The chemical basis of morphogenesis, Philos. T. R. Soc. Lon. B, 237, 37-72, doi:10.1016/S0092-8240(05)80008-4, 1952. van de Koppel, J. and Crain, C. M.: Scale-dependent inhibition drives regular tussock spacing in a freshwater marsh, The American Naturalist, 168, 136-147, doi:10.1086/508671, 2006. 